\title{
Evaluation of GanNan's Economic Development Efficiency based on DEA Method
}

\author{
Luning Ruan ${ }^{1,2}$, Zande $\mathbf{Y u}^{2}$ \\ ${ }^{1}$ Central China Development Research Center. Nanchang University, China \\ ${ }^{2}$ College of Economic and Management. Nanchang University, China \\ Email: ruanluning@ncu.edu.cn, ncueconomics_yu@163.com
}

\begin{abstract}
This paper, based on the DEA theory of $\mathrm{C}^{2} \mathrm{R}$ model and $\mathrm{BC}^{2}$ model, measures the total efficiency, pure technical efficiency, scale efficiency and it's stage of return to scale in eighteen counties of Gannan from 2007 to 2011. Then analyzing the input redundancy and output deficiency. Through empirical study, conclusion are as follow : (1) there are distinct differences on the efficiency of economic development among counties in Gannan; and in general, the efficiency of economic development, which shows as a downward trend, between 2009-2011 is lower than 2007-2008. (2)The output deficiency phenomenon is more serious than input redundancy phenomenon, and the input redundancy and output deficiency both show a upward trend during the near three years. Finally, policy suggestions are given based on the evaluation and analysis of efficiency of economic development in Gannan.

Index Terms - DEA, Gannan region, efficiency of economic development, regional development
\end{abstract}

\section{Introduction}

Imbalance of regional development is a problem with international universal significance. Ganzhou, which located in southern Jiangxi Province, is often called Gannan regions. Since China's reform and opening up police, Gannan region has undergone tremendous changes. However, for various reasons, it still obviously lags behind other developed regions in terms of economic and social development. Its economic output is low, industrial base is weak, infrastructure is poor, development of social undertakings lag behind, and poverty issue is outstanding. With the growing gap among the developed regions, the problem of imbalance of regional development is very prominent, thus to accelerate social and economic development in Gannan region is essential and urgent.

On June 28, 2012 the State Council approved "guidance on the support of revitalization and development in the Central Soviet Area among Gannan etc." to speed up the Central Soviet Area Gannan's revitalization and development. This is a major practice that thoroughly implements the concept of scientific development. The Eighteenth session of the People's Congress report claimed: "Strongly support the development of old revolutionary base areas, ethnic minority areas, border areas and poverty-stricken areas". The strategic decision made by CPC Central Committee and the State Council on the economic development of Gannan regions has far-reaching significance. The key to development of Gannan regions is to promote the development of social economy, and the core to enhance social and economic development is the efficient enhancement. From the economic perspective, the essence of process of regional economic development is the process of transformation from regional resources to capital, and the capital formation is essentially the transformation from surplus sectors to the deficit ones, and economic efficiency is the key determinant element of this. A good level of efficiency is a prerequisite for the use of resources and attracts social development funds, personnel and equipment, and the basic conditions for regional development is the revitalization of Gannan fundamental guarantee. Existing studies on regional economic development issues about Gannan regions is rare, and the economic developmental efficiency in Gannan region has not been studied yet. Therefore, study on the regional economic development of Gannan Rrgion in which former Central Soviet Area Gannan counties as the core is important. Especially with the support by central government, research on Gannan region's economic development efficiency has a practical significance for a better understanding of connotation of regional economic development and promotion of economic development efficiency and social development in Gannan regions, as well as provides theoretical references for government's decision-making.

\section{Literature Review}

By theory of macroeconomic growth, measurement on economic efficiency develops gradually by the study of contribution of productivity factors make to economic growth. Among them, the most representative is the Solow mode (Solow, 1957 [1]), "Solow residual" theory suggests that output growth per capita level of net capital-intensive growth in the unexplained portion classified as results of technological progress, which is called rate of technological progress. These unexplained parts are the so called "Solow residual", which also known as total factor productivity growth. Farrel first proposed frontier production function to measure technical efficiency in 1957. After that many scholars engaged in technical efficiency estimation methods, and they divided in two factions: the econometric method and mathematical programming. The most influential study of schools of econometric methods was conducted by Battese and Coelli (1995)[2] who proposed stochastic frontier production function method (SFA), which is closer to the actual situation of production and economic growth than traditional production function method, and factors that can affect TFP separated from its change rate, in-depth study of the causes of economic 
growth. Among all schools of mathematical programming, the commonly used method is data envelopment analysis (DEA), which based on linear programming duality theory estimates to put in more - and more effective output production frontier method without parameters.

\section{Gannan eighteen counties Empirical Analysis of Economic Development Efficiency}

In this paper, we selected eighteen counties in Gannan regions as the research objects, and evaluate the efficiency of the present economic development situation by using $\mathrm{C}^{2} \mathrm{R}$ model and $\mathrm{BC}^{2}$ model of DEA method.

\subsection{Index selection and data collection}

Economic development is a process of input-output production. In order to objectively evaluate the efficiency of Gannan regions' economic development, combined with evaluation of the representativeness, independence, operability, comparable and comprehensive systemic principles, and with the economic implications of indicators and data availability taking into account, we selected the following input and output indicators [3]:

Input indicators: input factors of economic development are the labour, material and capital. With "total population of $\mathrm{X} 1$ (million people)" index represents the total labour inputs; "total social fixed assets X2 (one hundred million Yuan)" index represents the total material inputs; "financial institutions loans X3 (one hundred million Yuan) "and" actual use of foreign X4 (\$ ten million), "index represents the amount of total investment capital.

Output indicators: use "GDP Y1 (one hundred million Yuan)", "commercial tax amounted Y2 (one hundred million Yuan)", "Retail sales Y3 (one hundred million Yuan)" and "annual wage Y4 (thousand Yuan)" index represents local economic system output.

This paper selected data of economic development of eighteen counties in Gannan regions during the period of 2007-2011 as a research object from the "Ganzhou City Statistical Yearbook,"(2007-2011) and the Statistical Yearbook of all countries.

\subsection{Model results}

According to the system above, this paper adopted the panel data of eighteen counties' economic development in Gannan regions during period 2007-2011 as the object; carrying out empirical analysis on the relative effectiveness of the country economic development's efficiency by using $\mathrm{C}^{2} \mathrm{R}$ and $\mathrm{BC}^{2}$ model. The paper uses the MaxDEA software to combat the model. Table 1 shows the efficiency of economic development throughout the overall efficiency, pure technical efficiency, pure scale efficiency and returns to scale, which stages its inputs redundancy and outputs deficiency.

Table 1 Gannan region's economic development efficiency DEA operation results (part)

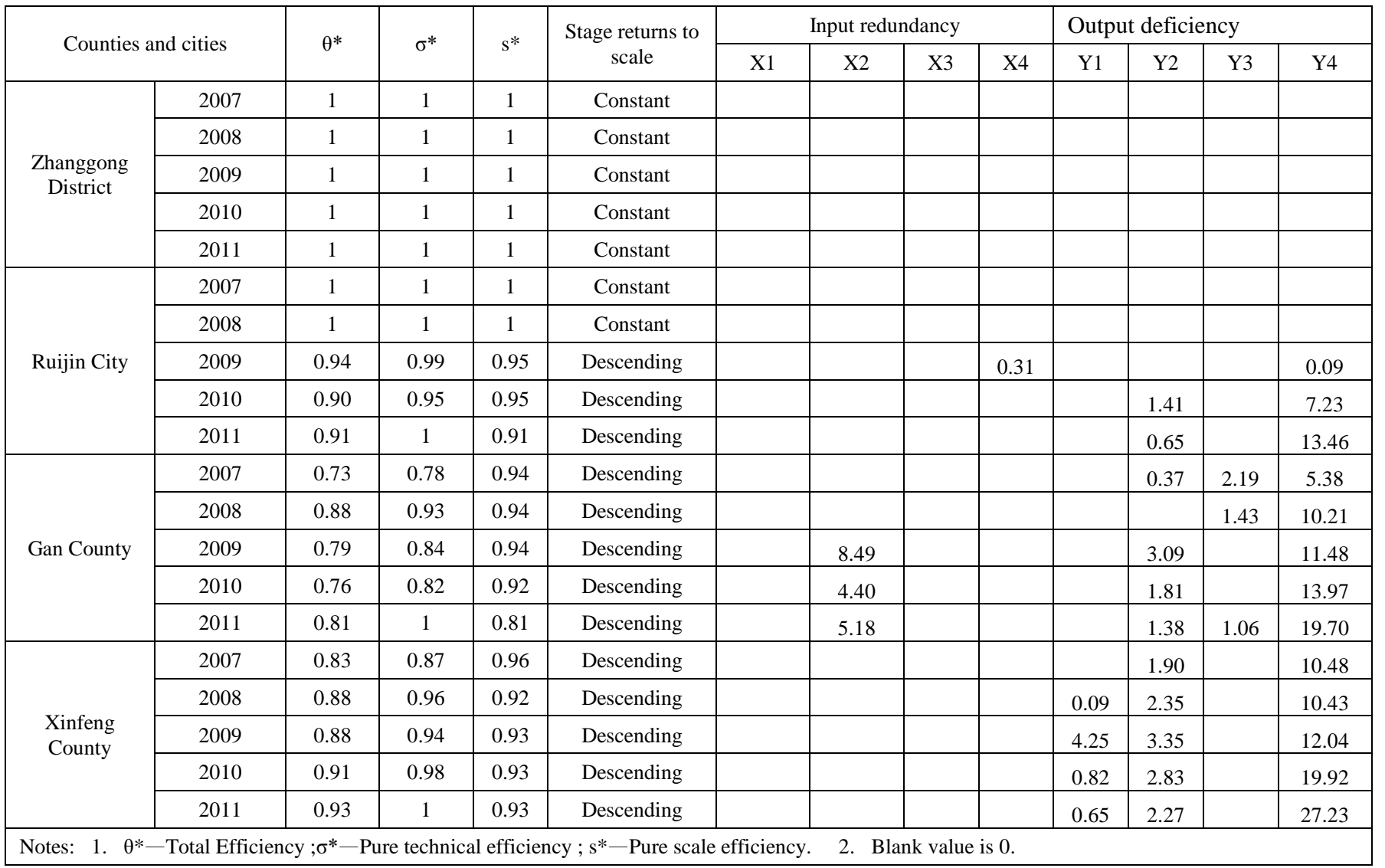


According to the average annual county overall efficiency value we divided into the following four levels:

Table 2 Gannan region's economic development level of overall efficiency classification

\begin{tabular}{|c|c|c|c|}
\hline Grade & $\theta^{*}$ & Counties & Proportion \\
\hline A & 1 & $\begin{array}{l}\text { Zhanggong District, Chongyi } \\
\text { County, Xunwu County }\end{array}$ & $16.7 \%$ \\
\hline B & $0.9-1$ & $\begin{array}{c}\text { Ruijin City, Dayu County, } \\
\text { Anyuan County, Longnan County, } \\
\text { Quannan County, Dingnan County, } \\
\text { Ningdu County, Yudu County, } \\
\text { Huichang County }\end{array}$ & $50 \%$ \\
\hline $\mathrm{C}$ & $0.8-0.9$ & Xinfeng County, Shangyou County & $11.1 \%$ \\
\hline $\mathrm{D}$ & $0.7-0.8$ & $\begin{array}{c}\text { Nankang City, Gan County, } \\
\text { Xingguo County, Shicheng County }\end{array}$ & $22.2 \%$ \\
\hline Notes: & \multicolumn{3}{|c|}{$\theta^{*}$-Total Efficiency } \\
\hline
\end{tabular}

\section{Analysis of Model Results}

\subsection{Analysis of efficiency}

According to Table 2, it shows significant differences among eighteen counties' economic development efficiency in Gannan regions. Overall, economic development efficiency in duration of 2009-2011 is lower than 2007-2008, which shows a downward trend. It also shows that the economic development efficiency in Gannan regions does not reach the optimal level. And the 2008's global financial crisis has a significant impact on the regions' economic development efficiency.

In duration of 2007-2011, average annual DEA of Zhanggong District, Chongyi County and Xunwu County are all efficient, which indicating nice efficiency of these three regions' economic development and technical efficiency. Meanwhile their scale efficiency have also reached the optimal level, in constant returns to scale stage. Study also found that GDP, financial income and social consumption levels and other indicators in Chongyi County and Xunwu County belong to the rearward relative to the level of economic development, but their efficiency is DEA effective. So regional economic development level of efficiency does not only depend on total economy amount, the level of economic development efficiency reflected its total economic output marginal increases under amount of investment.

In the non-DEA effective areas, the DEA is generally pure technical invalid. The scale of DEA invalid problem, which suggesting that on the one hand these regional economic development did not use full of existing resources, on the other hand, there are still exist excess or insufficient investment problem. From the perspective of technical efficiency, pure technical efficiency value $(\sigma)$ of Nankang City, Shangyou County, Anyuan County, Xingguo County and Shicheng County are relatively low, which is the main cause of invalid DEA overall efficiency. The phenomenon above shows resources in these areas are not optimal combined, and there are irrational industrial structure and irrational allocation of resources problems, which mainly because regional economic structure of agriculture and other low value-added industries account for a high proportion, and high-tech industries development lags behind, resulting in low levels of output .

From the point of view of scale efficiency, in 2011, seven counties were in constant returns to scale $(\mathrm{s}=1)$ phase, which means that their inputs are neither abundant nor insufficient, achieved the best returns to scale points. Scale efficiency in the other 11 counties is relatively ineffective ( $s<1)$, which reflects in recent years, during the process of urbanization, some counties exist "aggressive" phenomenon - their simply pursuit of GDP growth and urban expansion, overconcentration on resources in infrastructure, real estate and other industries, resulting in inefficient use of resources .

\subsection{Analysis of inputs redundancy and outputs deficiency}

Based on the evaluation index system in this study, Gannan counties, under the existing combinations of factor inputs, inputs and outputs of the redundant amount of the shortfall showed two trends: Firstly, input redundancy is more serious than output deficiency; secondly, phenomena of inputs redundancy and outputs deficiency are more severe in 20092011 than in 2007-2008. This is a reflection of non-DEA efficient pure technical inefficiency, scale regional invalidity and weak investment after the financial crisis.

From the input redundancy perspective, investment in fixed assets investment in the most serious redundancy, seven counties appear redundant investment in fixed assets, which including Gan County, Shangyou County, Dingnan County, Yudu County and Shicheng County. In 2011 the problem still existed, and even deteriorated in some counties and cities. This indicates that during urbanization process in Gannan Regions, social fixed assets investment factor inputs too much, there are over-investment (real estate fever, hot zone), resulted in a waste of resources and negatively affected the efficient use of resources. However, as on the aspect of loans of financial institutions, counties did not appear the input redundancy, which showed that financial market development in Gannan regions lagged behind, lack of financial resources, insufficient financial support, and can not meet the demand for financial capital of the new rural and urban construction process in Gannan regions.

As to output, due to low technical efficiency level and irrational resources structure, serious irrational insufficient output showed. In Xinfeng County, Shangyou County, Anyuan County, Longnan County, Quannan County, Dingnan County, Huichang County and Shicheng County, GDP output deficiency showed that total economic output and factor inputs do not match nor reach maximum capacity out. This is a direct manifestation of ineffective use of resources. The Non-DEA efficient counties show a prevalence of different levels of total lack of finances with deteriorating trend. Financial income and profits are related to tax. Lacking of finances reflects a low level of profitability and taxable 
capacity of enterprises, indicates the profitability is declining in the region, as well as decline of the regional economic development efficiency. In the aspect of social total consumption, seven counties' output, in which Shangyou County, Dingnan County and Shicheng County exacerbated in the recent years, are deficient in total retail sales of consumer goods, indicating a serious shortage of consumption in the related areas and there is considerable consumption potential untapped.

In summary, there is a significant difference among different countries in Gannan on efficiency of economic development. The non-DEA efficient counties always widespread irrational industrial structure and improper factor inputs problems. From the perspective of input redundancy and output deficiency, unreasonable fixed asset investment and lacking of loans from financial institutions are the main problems. While on the output side, there is a wide gap to optimal output on total GDP, financial revenue, consumption and wage levels .

\section{Policy Suggestions}

According to the analysis on evaluation of the economic efficiency of the eighteen counties in Gannan, suggestions are given as follows:

\subsection{Promote the urbanization, optimize investment structure}

Gannan regions widely exist urban and rural economic structure. The traditional urbanization, which mainly focuses on the population shift from rural to urban area, results in urban areas scale inconsistent with the level of economic development, and leads to inefficiency of economic development. Therefore, Gannan regions should promote the industrial agglomeration, urban and rural integrated development and innovation as the path of a new urbanization [4]. What's more, irrational industrial structure and investment inefficiency is quite conspicuous in Gannan regions. Agriculture accounts for a larger proportion in the national economy while the level of agricultural development is lagging behind. Therefore, government should establish a policy to encourage and support agricultural investment system and increase investment in agriculture. Finally, there exist problem of irrational structural of inputs and outputs in part of the counties. These counties should actively adjust and optimize the investment direction, guide enterprises to carry out technological innovation and industrial promotion, in order to prevent the generation industry bubble (such as real estate bubble), safeguard the sustainable development of regional economy.

\subsection{Perfect the county's financial system, strengthen the financial support}

The economic development in general lacks of financial support in Gannan regions .Therefore, the Government should speed up the financial reformation of commercial banks and strengthen economic development of the capital supply capacity of them; hand to develop and grow through local joint-stock banks, speed up rural banks, establish small loan companies and to meet individual industrial and commercial households' main micro, multi-level, diversified financial services needs. In the meantime, strengthening innovative financial services, providing convenient and practical financial products. Finally, the healthy development of the financial sector needs a good financial ecological environment. Gannan regions should perfect the financial legal system, develop and standardize the county guarantee, evaluation, notary and other intermediary agencies, promote the credit environment, strengthen financial supervision and financial ecological environment to build the county's long-term mechanism for regulating other ways to optimize the financial environment for the Gannan regional financial development of favourable external conditions.

\subsection{Vigorously develop the service industry}

Services industry in Gannan regions accounted for a low proportion of the national economy, failed to fully play its role in promoting employment, stimulating consumption, optimizing the industrial structure and promoting the process of urbanization. Therefore, to develop the service industry to promote the economic development is of great significance. Firstly, Gannan regions should suit one's measures to local conditions, make full use of existing resources, and vigorously develop the fruit industry, tourism and other traditional specialty services. Secondly, Gannan regions have rich "red" resources and ecosystems resources, which is suitable for the development of tourism. Finally, the government should promote market expansion and development of modern service industry environment, as well as the development of modern service industry and upgrade of industrial structure through the introduction of modern service industry development strategy, provision of tax incentives and optimization of the environment and open of services markets foundation. The level of development of modern service industry is a measure of the economy, an important indicator of the level of social modernization, the development of modern service industry to improve the regional economy overall operating efficiency and quality, and the transformation of economic growth mode play important roles.

\section{References}

[1] Solow R.M. Technical Change and the Aggregate Production Function. Review of Economics and Statistics, 1957, (39):312-320.

[2] Battese \& Colli, A Model for Technical Inefficiency Effects in a Stochastic Frontier for Planet Date, Empurcal Economics, Vol(20),1995

[3] Jianfang Mo \& Shiqi Ye, Application of DEA method for evaluating the development of regional economy. Systems Engineering, 2001(03).

[4] Ling Wu \& Chuanlong Han \& Chong Zhou, Research on the development path of the new urbanization in Central China Economic Zone. Contemporary World and Socialism, 2012 (06). 